\title{
POTRET MINAT LANJUTAN SEKOLAH: ANALISIS DAMPAK RENCANA PENETAPAN WILAYAH GARUT UTARA SEBAGAI KAWASAN INDUSTRI
}

\author{
Kurnia Muhamad Ramdhan ${ }^{1}$, RD. Ahmad Buchari², dan D. Anisa Sunija ${ }^{3}$ \\ ${ }^{1}$ Mahasiswa Prodi Pascasarjana Magister Kebijakan Publik, FISIP, Universitas Padjadjaran \\ ${ }^{2}$ Dosen Prodi Administrasi Publik, FISIP, Universitas Padjadjaran \\ ${ }^{3}$ Mahasiswa Prodi Sarjana Kesejahteraan Sosial, FISIP, Universitas Padjadjaran \\ E-mail: kurniamr@yahoo.com
}

\begin{abstract}
ABSTRAK. Tulisan ini merupakan hasil penelitian terhadap dampak dari rencana ditetapkannya wilayah Garut Utara sebagai kawasan industri. Fenomena cukup maraknya golongan ekonomi lemah di Garut Utara memunculkan kecenderungan kolektif bagi mayoritas lulusan Sekolah Menengah Atas untuk tidak melanjutkan pendidikan ke jenjang pendidikan tinggi. Kondisi tersebut kemudian semakin terdorong oleh ketersediaan lapangan kerja di daerahnya. Padahal jika merujuk pada PP Nomor 17 Tahun 2010 dijelaskan bahwa SMA dan MA memfasilitasi kebutuhan pembelajaran serta kompetensi yang diperlukan peserta didik untuk melanjutkan pendidikan pada jenjang pendidikan tinggi. Hal ini dapat berisiko menimbulkan bias penafsiran di masyarakat tentang perbedaan SMA/ MA dengan SMK/ MAK. Lebih jauh lagi, kualitas Sumber Daya Manusia yang dihasilkan tidak cakap sesuai dengan kapasitas pendidikannya. Penelitian ini menggunakan metode explanatory qualitative research yang berguna untuk membangun causal explanation. Hasil penelitian ini menunjukkan bahwa semenjak berdirinya beberapa pabrik industri yang ada di kawasan Garut Utara menimbulkan beragam penyebab yang mempengaruhi minat lanjutan sekolah para pelajar SMA dan MA, salah satunya adalah mayoritas dari siswa SMA/ MA di wilayah Garut Utara ini memilih untuk tidak melanjutkan studinya dan cenderung memilih untuk menjadi pegawai di pabrik saja.
\end{abstract}

Kata kunci: minat; pendidikan; kawasan industri

\section{PORTRAIT OF ADVANCED INTEREST IN STUDY: ANALYSIS OF THE IMPACT IN NORTH GARUT REGION PLAN AS AN INDUSTRIAL AREA}

\begin{abstract}
This paper is the result of research on the impact from the planned establishment of the Garut Utara region as an industrial area. The phenomenon of quite widespread weak economic groups in Garut Utara raises the desire for congregation for not to continue their education to higher education. This condition is further driven by the availability of employment in the area. Even if referring to PP No. 17 Tahun 2010, it is explained that SMA and MA facilitate learning needs and competencies needed by students to continue their education at the tertiary level. This can risk causing interpretation bias in the community about the difference between SMA/ MA and SMK/ MAK. Furthermore, the quality of Human Resources produced is incompetent according to their educational capacity. This research uses explanatory qualitative research method which is useful to build causal explanation. The results of the study show that there are a variety of causes that influence the continued interest in schooling of high school and MA students.
\end{abstract}

Key words: interest; education; industrial area

\section{PENDAHULUAN}

Adanya fenomena disorientasi lulusan Sekolah Menengah Atas (SMA) dan Madrasah Aliyah (MA) menjadi suatu aksioma di masyarakat, khususnya di masyarakat pedesaan yang secara perekonomian dan latar belakang pendidikan berbeda apabila dibandingkan dengan masyarakat perkotaan. Disorientasi disini berupa keputusan para siswa/i SMA dan MA yang setelah lulus cenderung tidak menempuh pendidikan lanjutan, sedangkan dalam PP Nomor 17 Tahun 2010 tentang Pengelolaan dan Penyelenggaraan Pendidikan pada Pasal 76 menjelaskan bahwa pendidikan menengah umum berfungsi untuk mempelajari ilmu pengetahuan dan teknologi (poin c) dan meningkatkan kesiapan fisik dan mental untuk melanjutkan pendidikan ke jenjang pendidikan tinggi dan/atau untuk hidup mandiri di masyarakat (poin f), kemudian dipertegas pada pasal 79 yang berbunyi penjurusan pada SMA, MA, atau bentuk lain yang sederajat berbentuk program studi yang memfasilitasi kebutuhan pembelajaran serta kompetensi yang diperlukan peserta didik untuk melanjutkan pendidikan pada jenjang pendidikan tinggi.

Hal ini kontras berbeda dengan definisi yang ada pada pasal dan poin yang sama untuk Sekolah Menengah Kejuruan (SMK) dan Madrasah Aliyah Kejuruan (MAK) yang lebih membekali peserta didik dengan kemampuan ilmu pengetahuan dan teknologi serta kecakapan kejuruan para profesi sesuai dengan kebutuhan masyarakat, meningkatkan kesiapan fisik dan mental untuk hidup mandiri di masyarakat dan/atau melanjutkan pendidikan ke jenjang pendidikan tinggi, dan penjurusannya berbentuk studi keahlian. Hingga saat ini memang belum ditemukan riset yang mengarah kepada hal tersebut, terlebih untuk mengkaji dampak jangka panjang terhadap tatanan sistem pendidikan nasional, namun bukan sebuah langkah yang cermat apabila disorientasi ini hanya dianggap sebuah kewajaran, karena dengan mewajarkan hal tersebut justru dapat membiaskan pendikotomian definisi sekolah menengah umum dan sekolah menengah kejuruan pada tataran praktis, lebih 
jauhnya lagi akan mempengaruhi pola pikir dan kualitas Sumber Daya Manusia (SDM).

Rencana lanjutan sekolah para lulusan SMA dan MA erat kaitannya dengan minat yang dimiliki, adapun minat dapat diartikan sebagai kecenderungan hati yang menetap dalam subjek atau tingkah laku seseorang untuk merasa tertarik pada bidang tertentu dan merasa senang berkecimpung dalam bidang itu (Djaali, 2011, p. 122; Slameto, 2003, p. 57; W. S. Winkel \& S.j, 1984, p.25). Pendapat tersebut diperkuat oleh Williams, K. C. (2013) bahwa "The fact is that human beings in general and students in particular are complex creatures with complex needs and desires". Crow dan Crow (1963), menyatakan ada 3 faktor yang mempengaruhi minat, yaitu sebagai berikut: a). Faktor dorongan atau keinginan dari dalam (inner urges); b). Faktor motif sosial (social motive); c). Faktor emosional (emotional motive).

Pendapat Crow dan Crow (1963) tersebut senada dengan Najafian, M. et.al, (2013) yang lebih spesifik mensegmentasikan faktor-faktor pendukung yang mempengaruhi minat dalam melanjutkan pendidikan yang lebih tinggi, dalam hasil penelitiannya menyatakan, 'Research results showed six factors which affect students' interest and direction towards higher education including individual factors, parents, friends, teachers, media and university's data," adapun dari enam faktor tersebut Penulis melakukan penelitian dalam empat lingkup faktor, yaitu faktor diri sendiri, keluarga, dan sekolah:

Faktor yang dipengaruhi dari dalam diri sendiri diantaranya motivasi, cita-cita dan keinginan, sejalan dengan pendapat tersebut dikuatkan oleh Suprapto (2007:12) bahwa "salah satu yang mempengaruhi minat adalah motivasi”. Hamalik (1992:173) mengungkapkan, motivasi adalah suatu perubahan energi dalam pribadi seseorang yang ditandai dengan timbulnya perasaan (afektif) dan reaksi untuk mencapai tujuan. Cita-cita adalah kehendak yang selalu ada di dalam pikiran seseorang dan akan selalu berusaha mencapainya. Keinginan sama dengan harapan. Pada saat ada keinginan dari siswa untuk melanjutkan ke perguruan tinggi maka siswa tersebut akan berusaha mencapai tujuan tersebut;

Faktor yang dipengaruhi lingkungan keluarga disebabkan beberapa hal diantaranya pendidikan keluarga dan ekonomi keluarga. Pendidikan keluarga yang tinggi akan mendukung kemauan anak bahkan akan mengarahkan potensi anak. Sedangkan kondisi ekonomi yang berkecukupan memudahkan orang tua dalam pembiayaan atau memilih perguruan tinggi yang diinginkan. Sejalan dengan Okioga, C.K. (2013), "Lower incomes families can have children who do not succeed to the levels of the middle income children have a greater sense of entitlement, more argumentative, or better prepared for adult life." Rendahnya pendapatan orang tua mempengaruhi keberhasilan anak. Diperkuat oleh DavisKean P.E. (2005), 'Parents' years of schooling also was found to be an important socioeconomic factor to take into consideration in both policy and research when looking at school-age children."; dan

Faktor yang mempengaruhi minat berdasarkan lingkungan sekolah terdiri dari tiga peran yaitu alumni, teman, dan guru yang mendukung dalam melanjutkan masuk perguruan tinggi. Alumni pada lingkungan sekolah berdampak pada ketertarikan pada siswa untuk memperoleh pandangan memilih perguruan tinggi. Teman dan guru merupakan pendukung dalam mencari informasi sebanyak-banyaknya.

Fenomena disorientasi ini semakin kentara di Kabupaten Garut bagian Utara, khususnya di Kecamatan Leles yang diwacanakan sebagai kawasan industri terluas yaitu 210,27 hektar. Wacana ini sudah mencuat sejak tahun 2016 di masa pemerintahan Bupati Rudy Gunawan dan Helmi Budiman ketika bermaksud untuk mengundang banyak investor menanamkan modalnya di Kabupaten Garut sebagai jalan untuk meningkatkan perekonomian daerah. Kabupaten yang tercatat memiliki jumlah pengangguran sekitar 65.700 orang ini kian gencar melakukan promosi terhadap para investor lokal maupun asing agar berminat untuk menanamkan modalnya. Hal ini tidak terlepas dari keinginan Pemerintah Kabupaten Garut untuk menyediakan lapangan pekerjaan seluasluasnya yang kemudian berimplikasi terhadap turunnya angka pengangguran serta menaikkan taraf perekonomian masyarakat.

Namun, maksud ini terganjal karena Rencana Tata Ruang Wilayah (RTRW) yang tidak memperkenankan Kabupaten Garut memiliki kawasan industri karena berdasarkan Peraturan Daerah Provinsi Jawa Barat Nomor 22/2010 tentang RTRW Provinsi Jawa Barat, dari luas wilayah Kabupaten Garut yang mencapai 307.407 hektar ditetapkan sebesar 81,39\% merupakan kawasan lindung dan diarahkan menjadi daerah unggulan. Dalam hal tersebut yang diprioritaskan yakni sektor pertanian dan industri pengolahan pertanian, perikanan dan industri pengolahan perikanan, wisata alam dan minat khusus, serta kegiatan pertambangan mineral logam dan non logam. Walaupun begitu, faktanya sudah berdiri beberapa pabrik berstatus Penanaman Modal Asing (PMA) di Kabupaten Garut yang sudah mulai beroperasi sejak tahun 2016, guna lebih menjangkau dan mempermudah para investor menanamkan modalnya maka Pemkab Garut mengajukan permohonan perubahan RTRW.

Pada tanggal 18-19 Januari 2017 telah dilaksanakan survei dan verifikasi lapangan calon lokasi kawasan industri yang akan ditetapkan dalam Revisi RTRW (RTRW) Kabupaten Garut Tahun 2011-2031. Survei diikuti berbagai unsur dari Pemerintah Kabupaten Garut, Pemerintah Provinsi Jawa Barat, perwakilan Kementerian Agraria dan Tata Ruang atau Badan Pertanahan Nasional, serta perwakilan Pusat Vulkanologi dan Mitigasi Bencana Geologi (PVMBG) Kementerian Energi dan Sumber Daya Mineral. Tujuan survei dan verifikasi ini yaitu untuk mendapatkan fakta lapangan sebagai masukan 
persetujuan substansi Menteri ATR/Kepala BPN terhadap rencana peruntukan kawasan industri dalam Revisi RTRW Kabupaten Garut Tahun 2011-2031. Adapun survei dan verifikasi ini melahirkan kesepakatan rekomendasi dalam Berita Acara tertanggal 19 Januari 2017 berdasarkan hasil fakta lapangan yaitu sekitar 510,21 hektar dari wacana semula seluas 1.313,97 hektar.

Terlepas dari hal itu, kini wilayah Garut Utara sudah mulai bertransformasi menjadi sebuah kawasan industri baru dengan segudang permasalahan, salah satunya adalah isu mengenai tenaga kerja. Tidak bisa dipungkiri bahwa adanya penyerapan tenaga kerja menjadi hal yang cukup mengundang masyarakat produktif untuk menjadi pekerja pada sektor ini. Kualifikasi pendidikan yang dibutuhkan juga lebih banyak pada lulusan SMA/sederajat. Fenomena tersebut menarik peneliti untuk kemudian memotret minat lanjutan sekolah sebagai dampak dari penetapan wilayah Garut Utara sebagai kawasan industri.

\section{METODE}

Metode penelitian yang digunakan dalam riset ini yaitu melalui pendekatan explanatory qualitative research, hal ini didasarkan pada perumusan masalah yang menuntut untuk melakukan berbagai aktivitas eksplorasi dalam rangka memahami dan menerangkan gejala-gejala tertentu yang menjadi fokus penelitian ini. Penelitian dengan pendekatan kualitatif dipilih guna lebih melihat makna, artian (meaning) dari permasalahan, yang berguna untuk membangun causal explanation. Pendekatan kualitatif bertujuan memahami suatu situasi sosial atau permasalahan sosial, yang dibentuk berdasarkan pandangan informan.

Bukan tanpa alasan mengapa penelitian kualitatif lebih dipertimbangkan, Penulis sudah berupaya menggunakan pendekatan kuantitatif namun pada saat melakukan observasi di lapangan ternyata tidak sesuai ekspektasi, sehingga dalam pemilihan informan pun dilakukan accidental sampling terhadap para siswa/i kelas XII dan lebih diarahkan kepada penelitian kualitatif. Penulis pada saat itu melakukan penelitian pada rentang 7 hari sebelum Ujian Nasional guna mendapatkan kualitas data yang lebih baik, namun kenyataannya tidak semua informan dapat ditemui. Dari 12 sekolah yang tersebar di 3 kecamatan, hanya 3 sekolah yang tersebar di 2 kecamatan saja yang dapat Penulis dapatkan datanya, yaitu SMA YKBBB yang berlokasi di Jalan Raya Tutugan Leles, Haruman Leles, MAAl Muamalah yang berlokasi di Jalan Raya Leuweungtiis, dan MAS Ma'arif yang berlokasi di Kecamatan Kadungora. Hal ini disebabkan keterbatasan ruang, waktu, dan kendala lainnya yang tidak terprediksi. Data primer Penulis dapatkan melalui wawancara terstruktur. Berikut ini Penulis sajikan perbandingan banyaknya populasi dan informan yang berhasil di wawancarai.
Tabel 1. Jumlah Informan

\begin{tabular}{lccl}
\hline & $\begin{array}{c}\text { SMA YKBBB } \\
\text { Leles }\end{array}$ & $\begin{array}{c}\text { MA Al } \\
\text { Muamalah } \\
\text { Leles }\end{array}$ & $\begin{array}{c}\text { MAS Ma'arif } \\
\text { Kadungora }\end{array}$ \\
\hline Jumlah Populasi & 177 orang & 34 orang & 117 orang \\
Jumlah Informan & 29 orang & 21 orang & 55 orang \\
\hline
\end{tabular}

Adapun pertanyaan kepada informan telah tersusun dalam pertanyaan terstruktur seperti berikut ini.

Apakah kamu akan melanjutkan pendidikan ke Perguruan Tinggi?

Apakah alasan biaya menjadi salah satu faktor penyebab?

Apakah keinginan keluarga menjadi salah satu faktor penyebab?

Apakah alasan untuk segera menikah menjadi salah satu faktor penyebab?

Apakah sekolah mendorong Kamu untuk melanjutkan ke Perguruan Tinggi?

Apakah sekolah mendorong Kamu untuk langsung bekerja?

Apakah Kamu tertarik untuk bekerja menjadi karyawan pabrik?

Apakah kamu akan bekerja di pabrik?

Apakah obsesi Kamu untuk melanjutkan atau tidak melanjutkan ke perguruan tinggi dipengaruhi oleh lingkungan pertemanan di sekolah Kamu?

Apakah obsesi Kamu untuk melanjutkan atau tidak melanjutkan ke perguruan tinggi dipengaruhi oleh lingkungan masyarakat di tempat tinggal Kamu?

Apakah Kamu tahu bahwa terdapat beasiswa perkuliahan?

Data kemudian dicacah menjadi dua bagian, mengacu pada jawaban pertanyaan nomor satu, yaitu yang akan melanjutkan pendidikan dan yang tidak akan melanjutkan pendidikan. Adapun data sekunder penulis dapatkan melalui dokumen atau sumber lain yang relevan.

\section{HASIL DAN PEMBAHASAN}

Adanya rencana penetapan wilayah Garut Utara sebagai kawasan industri, membawa perubahan pada masyarakat yang cukup signifikan. Salah satu unsur masyarakat yang terkena pengaruh adalah para lulusan SMA/sederajat di wilayah sekitar. Adanya alternatif pilihan pekerjaan menjadi buruh pabrik sedikit banyak mengubah minat para pelajar ini. Penelitian dilakukan untuk memotret minat lanjutan sekolah para pelajar di wilayah sekitar Garut Utara. Penulis mencoba membagi pembahasan ke dalam dua bagian yaitu pelajar yang berminat melanjutkan pendidikan dan pelajar yang tidak berminat melanjutkan pendidikan. 
Pelajar yang Berminat Melanjutkan Pendidikan

Berikut ini adalah grafik yang berisikan informasi mengenai jawaban informan yang memiliki minat untuk melanjutkan pendidikan.

Dengan membaca data pada gambar 1, dari ketiga sekolah dapat disimpulkan bahwa kebanyakan dari mereka beranggapan bahwa biaya kuliah menjadi faktor penyebab melanjutkan kuliah. Keadaan ekonomi keluarga erat hubungannya dengan belajar anak karena anak yang sedang belajar harus terpenuhi kebutuhan pokok dan fasilitas belajar, hal itu hanya dapat terpenuhi jika keluarga tersebut mempunyai cukup dana. Apalagi jika dilihat dari segi biaya perguruan tinggi yang begitu cukup mahal dan dengan biaya kuliah yang beragam tidak semua orangtua memiliki pendapatan yang cukup untuk menyekolahkan anak-anaknya hingga ke jenjang perkuliahan. Informan yang menjawab faktor biaya besar kemungkinan dapat dipicu karena keluarga informan berasal dari keluarga mampu secara finansial. Kemudian, dari hasil penelitian menunjukkan bahwa keluarga menjadi faktor para informan untuk melanjutkan kuliah lebih banyak dan hanya sedikit dari informan yang menjawab bahwa faktor keluarga tidak mempengaruhi keinginan para informan untuk melanjutkan kuliah. Dalam hal ini minat dalam melanjutkan studi tumbuh dari keluarga yang juga memiliki kepedulian yang tinggi pada pendidikan.

Lalu dari hasil penelitian juga ditemukan bahwa sebagian besar informan yang memiliki minat melanjutkan studi menjawab bahwa pihak sekolah menjadi faktor pendorong para informan untuk melanjutkan studi ke jenjang perguruan tinggi. Kemudian, faktor lingkungan pertemanan juga rupanya menjadi salah satu pendorong minat melanjutkan studi, dan bagi mereka faktor lingkungan tempat tinggal cukup berpengaruh terhadap minat lanjutan studi. Hal ini terjadi karena kemungkinan lingkungan tempat tinggal mereka terdapat orang-orang yang juga sedang menempuh pendidikan lanjutan.

Perihal adanya beasiswa perkuliahan, banyak informan yang ternyata sudah mengetahui adanya beasiswa tersebut. Hanya sedikit dari seluruh informan yang menjawab bahwa mereka tidak mengetahui adanya beasiswa perkuliahan. Maka, dapat disimpulkan bahwa adanya beasiswa menjadi faktor mereka untuk melanjutkan studi, meskipun mereka bukan dari keluarga yang berada tetapi keinginan dan tekad yang kuat untuk melanjutkan studi dapat dipengaruhi juga oleh adanya beasiswa perkuliahan. Informan yang Tidak Akan Melanjutkan Pendidikan. Berikut ini gambar 2. yang berisikan informasi mengenai jawaban informan yang tidak memiliki minat untuk melanjutkan pendidikan.

Dengan membaca data pada grafik tersebut, dari ketiga sekolah dapat disimpulkan bahwa hampir seluruh informan menjawab bahwa alasan biaya adalah faktor yang mempengaruhi mereka untuk tidak melanjutkan studi ke perguruan tinggi. Selain itu, lebih dari setengah informan menjawab bahwa faktor keinginan keluarga menjadi salah satu faktor mereka untuk tidak melanjutkan kuliah. Hal ini menunjukkan bahwa sebagian besar keluarga informan menjadi pengaruh bagi mereka untuk tidak melanjutkan studi. Jika dikorelasikan dengan poin pertama, besar kemungkinan para informan yang tidak melanjutkan studi dipengaruhi oleh keluarga yang keadaan ekonominya tidak mampu untuk membiayai para informan untuk melanjutkan studi. Adapun dari keseluruhan informan yang tidak akan melanjutkan studi ke perguruan tinggi, sebagian besar tidak menjadikan alasan untuk segera menikah menjadi faktor penyabab tidak akan melanjutkan studi.

Dari hasil penelitian ditemukan bahwa meskipun sekolah-sekolah telah mendorong untuk melanjutkan

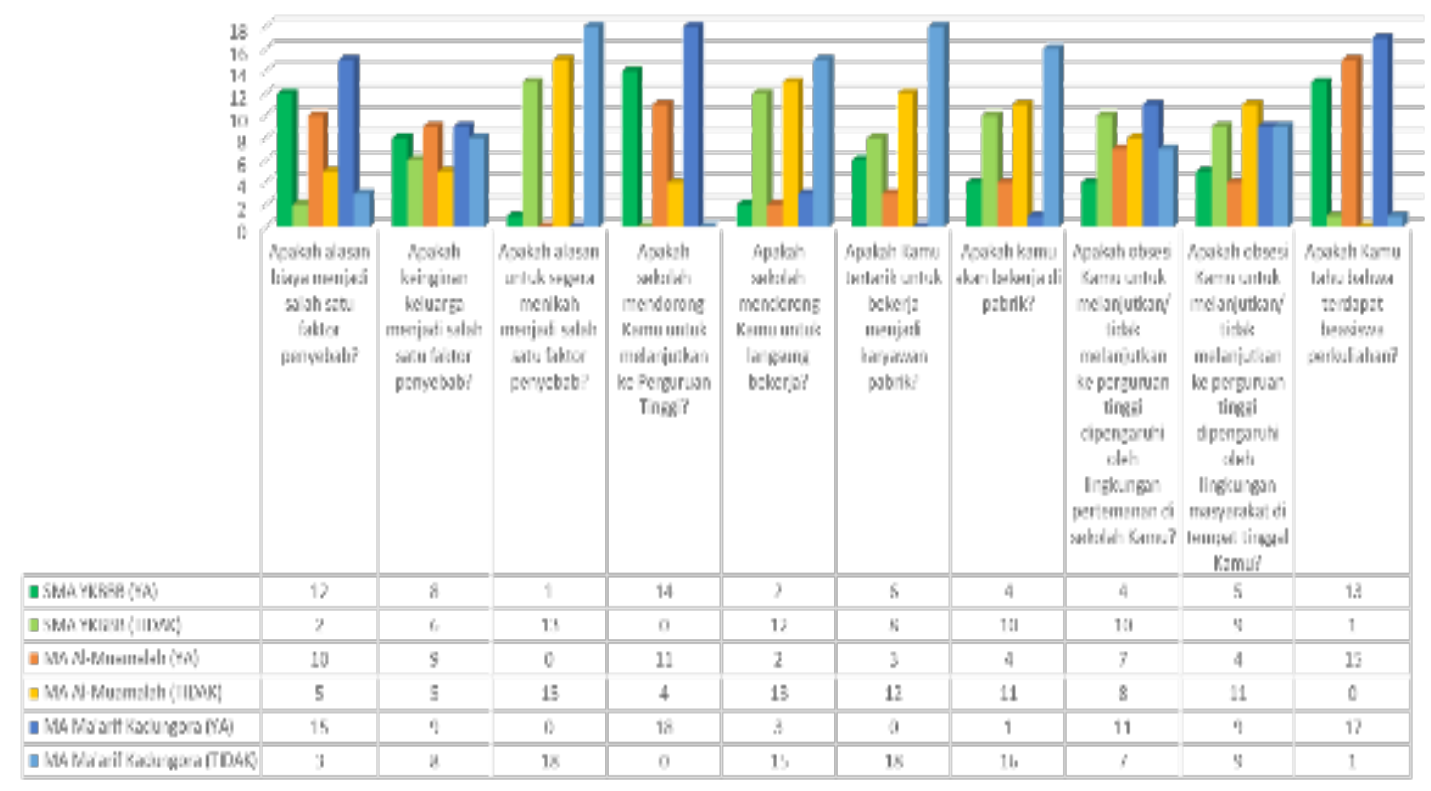

(Hasil olah Penulis, 2018)

\section{Gambar 1. Ikhtisar Jawaban Informan yang Akan Melanjutkan Pendidikan}

Potret Minat Lanjutan Sekolah: Analisis Dampak Rencana Penetapan Wilayah Garut Utara sebagai Kawasan Industri (Kurnia Muhamad Ramdhan, RD. Ahmad Buchari dan D. Anisa Sunija) 


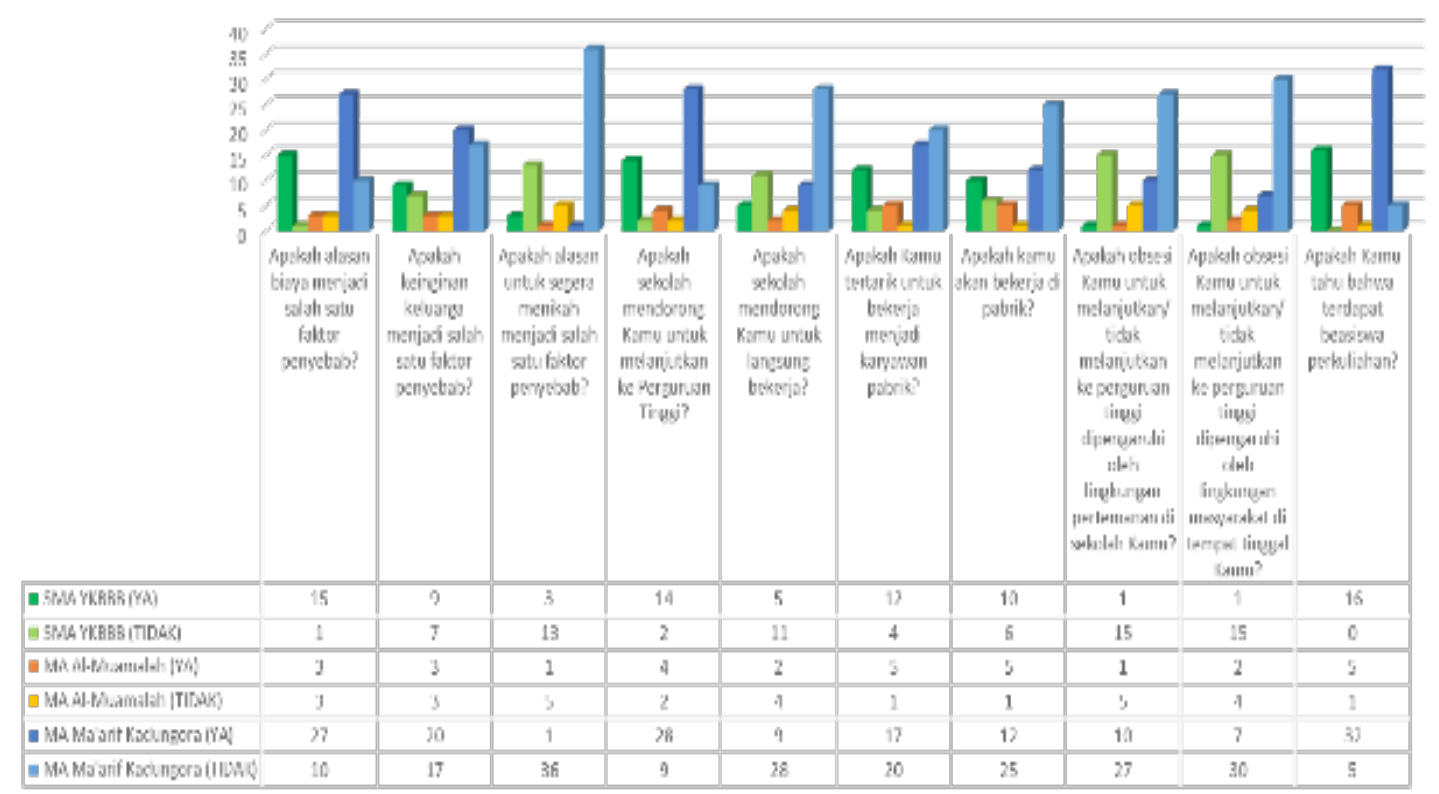

Gambar 2. Ikhtisar Jawaban Informan yang Tidak Akan Melanjutkan Pendidikan

(Hasil olah Penulis, 2018)

studi, tetapi itu tidak cukup mendorong para informan untuk melanjutkan studi. Minat dari informan yang menjawab demikian ternyata berbeda dari apa yang sudah sekolah usahakan. Ada faktor lainnya yang mungkin menyebabkan mereka tidak memiliki minat melanjutkan studi. Kemudian, sebagian besar para informan dari masing-masing sekolah menjawab bahwa mereka tertarik untuk menjadi karyawan pabrik, dan sebagian kecil lainnya tidak tertarik untuk menjadi karyawan pabrik. 92\% dari 29 informan yang berasal dari SMA YKBBB menjawab bahwa mereka tertarik untuk menjadi karyawan pabrik, sedangkan $8 \%$ informan tidak tertarik. Sedangkan di MA Ma'arif menjawab bahwa hanya 17 orang informan yang tertarik untuk menjadi karyawan pabrik sedangkan sebanyak 20 orang lainnya tidak tertarik, kemudian dari MA Al Muamalah, sebanyak 5 informan menjawab bahwa mereka tertarik untuk menjadi karyawan pabrik, sedangkan 1 orang lainnya tidak tertarik untuk menjadi karyawan pabrik. Dari hal tersebut dapat dilihat bahwa yang paling banyak memiliki ketertarikan untuk bekerja di pabrik adalah informan dari SMA YKBBB dan MA Al Muamalah. Hal tersebut logis terjadi karena lokasi sekolah mereka yang dekat dengan pabrik.

Lalu, dari hasil penelitian ditemukan bahwa sebagian besar informan beralasan mereka tidak melanjutkan studi adalah bukan karena faktor lingkungan pertemanan. Selain itu, sebagian besar informan juga mengatakan bahwa lingkungan masyarakat di sekitar tempat tinggal bukan merupakan alasan mereka tidak melanjutkan studi. Terkait hal ini, faktor tidak adanya biaya kembali menjadi penyebab yang paling signifikan untuk mempengaruhi minat lanjutan studi. Berkaitan dengan beasiswa, sebagian besar para informan memiliki pengetahuan akan adanya beasiswa perkuliahan. Namun, adanya beasiswa perkuliahan tetap saja tidak mempengaruhi mereka untuk tidak melanjutkan studi.

\section{SIMPULAN}

Rencana tentang penetapan wilayah Garut Utara sebagai kawasan industri membawa konsekuensi perubahan pada berbagai hal, salah satunya yaitu mengenai minat lanjutan sekolah para pelajar SMA/MA di kawasan Garut Utara. Hasil studi penelitian ini menunjukkan bahwa semenjak berdirinya beberapa pabrik industri yang ada di kawasan Garut Utara menyebabkan sebagian masyarakat terpengaruhi oleh beragam penyebab yang menimbulkan minat lanjutan sekolah minim. Sebagian masyarakat dalam hal ini pelajar yang memiliki minat untuk melanjutkan studi, mereka mendapatkan pengaruh dari keluarga, sekolah, masyarakat dan lingkungan pertemanan untuk melanjutkan studi ke perguruan tinggi. Hal ini menjadi faktor pendorong bagi mereka untuk melanjutkan studi. Kemudian, ada juga yang tidak akan melanjutkan studi, meskipun telah mendapat dorongan dari berbagai pihak seperti dari lingkungan sekolah dan lingkungan masyarakat agar mereka dapat melanjutkan sekolah. Alasan utama penyebab hal tersebut adalah biaya dan dukungan keluarga. Kemudian, adanya pabrik yang dekat dengan tempat tinggal ternyata mempengaruhi pemikiran mereka bahwa setelah lulus akan bekerja di pabrik.

Hal yang sangat mungkin bahwa ada pelajar yang ingin melanjutkan sekolah namun terhalang berbagai hal. Adanya dorongan dari pihak sekolah dapat membantu para siswanya agar tetap melanjutkan studi dengan melakukan mediasi dengan orang tua para siswa. Hal ini juga dapat didorong dengan adanya pemahaman mengenai beasiswa perkuliahan yang akan membantu memudahkan keluarga 
dalam hal biaya. Karena para informan sendiri memiliki pengetahuan akan adanya beasiswa yang mana beasiswa ini dapat dijadikan alternatif pilihan yang tepat untuk meringankan keuangan keluarga.

Persoalan yang timbul dari daerah industrialisasi baru dengan kondisi perekonomian masyarakat yang belum maju tentu perlu menjadi bagian dari perhatian dan tanggung jawab pemegang otoritas. Berkaitan dengan hal ini, pemegang otoritas perlu memberikan proteksi dan bertanggungjawab atas pembentukan Sumber Daya Manusia yang berkualitas untuk kehidupan masyarakat yang lebih baik.

\section{UCAPAN TERIMA KASIH}

Penulis mengucapkan rasa syukur dan terima kasih yang sebesar-besarnya kepada Dian Rahman Ramadan yang telah membantu Penulis dalam penelitian di lapangan. Serta kepada pihak SMA YKBBB Leles, MA Al Muamalah Leles, dan MAS Ma'arif Kadungora yang telah memberikan izin Penulis untuk melakukan penelitian.

\section{DAFTAR PUSTAKA}

Berita Acara Kesepakatan Hasil Survei dan Verifikasi Lapangan Calon Lokasi Kawasan industri dalam Revisi Rencana Tata Ruang Wilayah (RTRW) Kabupaten Garut Tahun 2011-2031. (2017, Januari 19).

Crow, L.D. (1963). Educational Psychology. New York: American Book Company.
Davis-Kean, P. (2005). The influence of perent education and family income in chils achievement: the indirect role of parental expectations and the home environment. Journal of Family Psychology, 19, (2), 294-304.

Djaali, H. (2011). Psikologi Pendidikan. Jakarta: Bumi Aksara.

Hamalik, O. (2004). Proses belajar mengajar. Jakarta: Bumi Aksara.

Najafian, M.d. (2013). Factors affecting increase (decrease) in interest and guiding students towards higher education. Australian Journal of Basic and Applied Sciences, 7, (7), 980-985.

Okioga, C.K. (2013). The impact of students's socioeconomic background on academic performance in Universities, a case of students in Kisli University Collage. American International Journal of Social Science, 2, (2), 38-46.

PP Nomor 17 Tahun 2010, tentang Pengelolaan dan Penyelenggaraan Pendidikan. (t.thn.).

Slameto, (2003). Belajar dan faktor-faktor yang mempengaruhi. Jakarta: Rineka Cipta.

Williams, K. (2013). Five key ingredients for improving student motivation. Research in Heigher Educational Journal, 104-122.

Winkel, S. \&. (1984). Psikologi Pendidikan dan Evaluasi Belajar. Jakarta: Gramedia. 